\title{
Improvement the Performance of the Power System by using an TCSC Device
}

\author{
Dr. Ali Abdulwahhab Abdulrazzaq \\ (Technical Instructors Training Institute / Middle Technical University, Baghdad, Iraq)
}

\begin{abstract}
This paper presents the performances of the Thyristor Controlled Series Compensator (TCSC) in controlling the loading under various perturbations that may occur in the transmission power system. By controlling the line reactance, TCSC is indirectly contributing to the enhancement of the loading capability of the transmission network. Simulations were performed on the test network called TEST2 using the EUROSTAG software. Both static and dynamic simulations were performed, while analyzing the voltage control and the change in the active power under various disturbances, as well as the power losses under steady-state.
\end{abstract}

Keywords: Thyristor Controlled Series Compensator (TCSC), Power System stability.

\section{Introduction}

Transmission line congestion is one of most major difficulties in the operation of restructured power systems. In a competitive Power market, the power system is called congested when participant of electric energy desire to produce and consume in amounts that would cause the transmission system to operate at or beyond one or more transfer limits and as a result some economic generators become unemployable [1]. To overcome this difficulty and optimal usage of existent transmission grid, Power systems have exploited series FACTS devices to increase lines load ability. As a result, power system operators can use current transmission systems at their maximum thermal capability [2].

Series Flexible AC Transmission Systems (FACTS) devices such as Thyristor Controlled Series Compensation (TCSC) can have a significant impact on operational flexibility and controllability of the power system. They can dynamically change the total reactance of transmission lines and control the power flow through lines in a way to increase the transient stability margins and make the system more secure. Power flow in Electrical Power System can be improved by adjusting reactance parameter of the transmission line. It can also be enhanced by adding a new transmission line in parallel with the existing one [3]. Thyristor Controlled Series Capacitor (TCSC) is one such device, which offers smooth and flexible control of the line impedance with much faster response compared to the traditional control devices. While there have been numerous studies concerning the utilization of these devices, so far, most of the research has focused on issues such as transient stability improvement, sub-synchronous resonance (SSR) mitigation, damping of power swings, avoiding voltage collapse and controlling power flows, etc [4],[5].

FACTS devices, such as controllable series capacitors TCSC can help to reduce the transmission congestion, resulting in an increased loadability, low system loss, improved stability of the network, decreased cost of production and fulfilled contractual requirement [6]. There have been several of these FACTS devices applied to real power systems in the United States and other places [7]. A TCSC was installed at Kayenta substation in Arizona to compensate its $300 \mathrm{~km}, 230 \mathrm{kV}$ transmission line. This TCSC was used to evaluate transmission line capacity enhancement, power flow control, and damping of sub-synchronous resonance [8]. Similar system has been installed in Slatt substation in Oregon [9]. In China, a TCSC is applied at Fengtun station for the 500kV Yimin - Fengtun line [10]. The TCSCs are still under evaluation for power system stabilization to prove it effective for capital investment reduction [11].FACTS can improve both dynamic and static performance of the system. Optimal location of FACTS has been investigated in many researches. Static indexes such as system cost, system loadability and voltage deviation have been optimized in many papers.In [12] the optimal location, type and values are determined to improve loadability of the system.[13] optimizes the location of FACTs to minimize the overall system cost, which compromises of generation cost and investment cost. [14] uses a multi objective of total fuel cost, power losses and system loadability. In this research optimal location of FACTS devices are determined to improve only static criteria. Allocating FACTS to improve dynamic indexes haven't been wholly considered, yet.

\section{Modeling The Tesc Compensator}

The variable series compensation is highly effective in both controlling power flow in the line and in improving stability. With series compensation the overall effective series transmission impedance from the sending end to the receiving end can be arbitrarily decreased thereby influencing the power flow,

$$
P=U^{2} / X \sin \sigma
$$


Thyristor Controlled Series Capacitor (TCSC) is an important FACTS component which makes it possible to vary the apparent impedance of a specific transmission line [15].

\section{A .Steady-state model}

The IEEE defines the TCSC as a capacitive reactance compensator which consists of three main components, capacitor bank C, bypass inductor L and bidirectional thyristors SCRI and SCR2. Series capacitive compensation has been used to increase line power transfer as well as to enhance system stability.TCSC have many different structure, one of this basic formulation is shown in figure.1, shown that affixed capacitor and parallel connected of TCR., A parameter to describe the TCSC main circuit is which is the quotient of the resonant frequency and the network frequency resulting in,

$$
\lambda=\sqrt{\frac{-X_{C}}{X_{L}}}
$$

where,

$$
X_{C}=-\frac{1}{W_{C}} \quad \text { and } X_{L}=W_{L}
$$

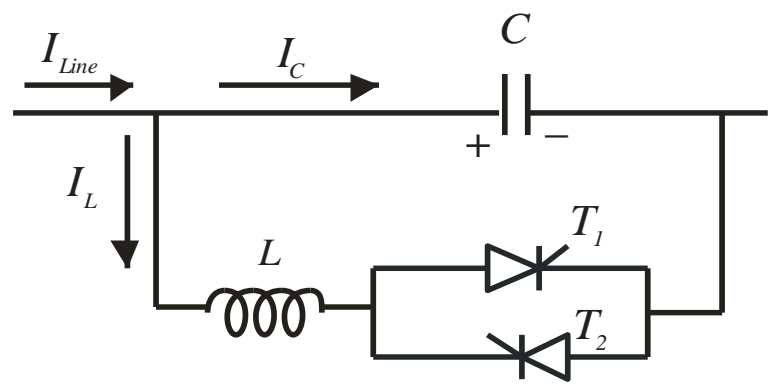

Fig.1 Thyristor-Controlled Series Capacitor TCSC.

TCSC is a device connected in series with a transmission line. It can change the line reactance $X_{\text {line }}$ and therefore is able to control the active power flowing over the line [16].

TCSC consists of several modules built of a fixed capacitance in parallel with a thyristor controlled inductor . Therefore, the equivalent reactance $X_{e q}$ of each individual module is considered which is determined by the firing angle of the thyristors by,

$$
X_{e q}(\alpha)=\frac{-1}{B_{L}(\alpha)+B_{C}}
$$

where

${ }^{B}{ }_{L}(\alpha)=-\frac{1}{W_{L}}\left(1-\frac{2 \alpha}{\pi}-\frac{\sin (2 \alpha)}{\pi}\right) \quad, \quad{ }^{B} C=W_{C}$

For the total reactance value of the TCSC, the equivalent reactances of the modules are added. As each module is controlled separately, the unavailable band around zero can be covered. Thus, the device is modeled as a variable reactance $X_{T C S C}$ connected in series with the line, as in Figure 2 the total reactance $X_{\text {line }}$ of the line including the TCSC is therefore,

$$
X_{\text {line }}=X+X_{T C S C}
$$

where,

$\mathrm{X}$ is the reactance of the line without the TCSC installed.

The reactance XTCSC is limited to the domain,

$$
X_{T C S C, \max } \leq X_{T C S C} \leq X_{T C S C, \min }
$$

where the values of $X_{T C S C, \min }$ and $X_{T C S C, \max }$ are determined by the size of the TCSC device and the characteristics of the line in which it is placed, since due to the physics the allowed compensation rate of the line is limited [17].

This range is set to $40 \%$ inductive and $90 \%$ capacitive. Therefore, the final constraint on the effective 
reactance $X_{T C S C}$ is,

$\max \left(-0.9 X, X_{T C S C \min }\right) \leq X_{T C S C} \leq \min \left(0.4 X, X_{T C S C \max }\right)$

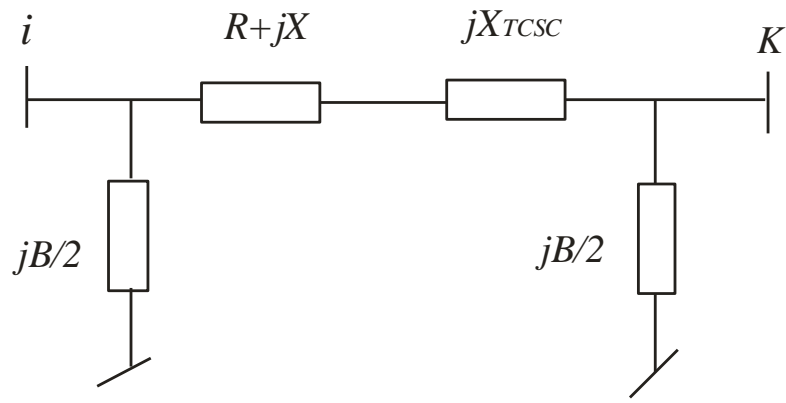

Fig.2 modeling of TCSC.

\section{Case Study}

The simulation was performed on the test network called TEST 2, which consists of 13 buses, 15 transmission lines (single and double circuit), 8 loads and 5 generating units. The slack bus is associated to bus 12. The total active power generation is $1291 \mathrm{MW}$, and the total active power load is $1265 \mathrm{MW}$. The network nominal voltage is $220 \mathrm{kV}$ Figure 3 illustrates the one-line diagram of the test network [18].

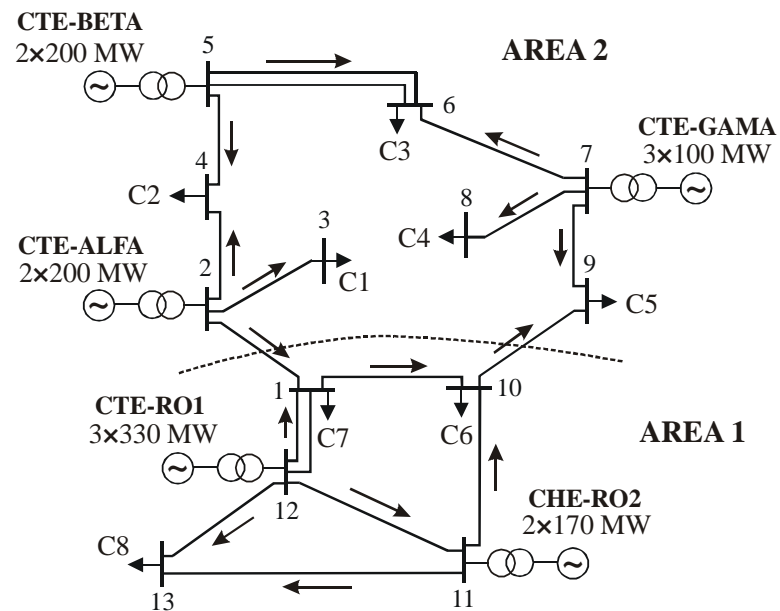

Fig. 3 one-line diagram of TEST 2

The branch data of the test network are presented in Table I, and the bus data are presented in Table II.

Table. I. Branch data

\begin{tabular}{|c|c|c|c|c|c|c|}
\hline From & To & $\mid \begin{array}{ll}\text { No. } & \text { of } \\
\text { circuits }\end{array}$ & $\begin{array}{l}\text { Length } \\
{[\mathrm{km}]}\end{array}$ & $\begin{array}{l}R \\
{[\Omega]}\end{array}$ & \begin{tabular}{|l}
$X$ \\
{$[\Omega]$}
\end{tabular} & $\begin{array}{l}B \\
{[\mu \mathrm{S}]}\end{array}$ \\
\hline 1 & 2 & \begin{tabular}{|l|}
1 \\
\end{tabular} & 150 & 9.9 & 60.6 & 416 \\
\hline 2 & 3 & 1 & 80 & 5.3 & 32.3 & 222 \\
\hline 2 & 4 & 1 & 112 & 7.1 & 45.2 & 311 \\
\hline 5 & 6 & 2 & 100 & 3.3 & 20.9 & 544 \\
\hline 6 & 7 & 1 & 90 & 6.65 & 37.9 & 243 \\
\hline 7 & 8 & 1 & 70 & 4.6 & 28.3 & 195 \\
\hline 7 & 9 & 1 & 60 & 4 & 24.2 & 167 \\
\hline 9 & 10 & 1 & 80 & 5.3 & 32.3 & 222 \\
\hline 1 & 10 & 1 & 75 & 5.5 & 31.5 & 202 \\
\hline 10 & 11 & 1 & 120 & 7.9 & 48.5 & 333 \\
\hline 11 & 13 & 1 & 80 & 5.3 & 32.3 & 222 \\
\hline 11 & 12 & 1 & 55 & 3.6 & 22.2 & 153 \\
\hline 12 & 13 & 1 & 83 & 5.5 & 33.5 & 230 \\
\hline 1 & 12 & 2 & 150 & 4.9 & 31.4 & 812 \\
\hline 4 & 5 & 1 & 60 & 4 & 24.2 & 167 \\
\hline
\end{tabular}


Table. II. Bus data

\begin{tabular}{|l|l|l|l|l|l|l|l|}
\hline $\begin{array}{l}\text { Bus } \\
\text { No. }\end{array}$ & Type & $\begin{array}{l}P_{c} \\
{[\mathrm{MW}]}\end{array}$ & $\begin{array}{l}Q_{c} \\
{[\mathrm{MVAr}]}\end{array}$ & $\begin{array}{l}P_{g} \\
{[\mathrm{MW}]}\end{array}$ & $\begin{array}{l}U_{s p} \\
{[\mathrm{kV}]}\end{array}$ & $\begin{array}{l}Q_{\min } \\
{[\mathrm{MVAr}]}\end{array}$ & $\begin{array}{l}Q_{\max } \\
{[\mathrm{MVAr}]}\end{array}$ \\
\hline 1 & $\mathrm{C}$ & 250 & 155 & 0 & 220 & 0 & 0 \\
\hline 2 & $\mathrm{G}$ & 0 & 0 & 255 & 230 & 0 & 190 \\
\hline 3 & $\mathrm{C}$ & 60 & 35 & 0 & 220 & 0 & 0 \\
\hline 4 & $\mathrm{C}$ & 190 & 130 & 0 & 220 & 0 & 0 \\
\hline 5 & $\mathrm{G}$ & 0 & 0 & 240 & 225 & 0 & 180 \\
\hline 6 & $\mathrm{C}$ & 220 & 135 & 0 & 220 & 0 & 0 \\
\hline 7 & $\mathrm{G}$ & 0 & 0 & 240 & 225 & 0 & 180 \\
\hline 8 & $\mathrm{C}$ & 65 & 35 & 0 & 220 & 0 & 0 \\
\hline 9 & $\mathrm{C}$ & 130 & 70 & 0 & 220 & 0 & 0 \\
\hline 10 & $\mathrm{C}$ & 200 & 140 & 0 & 220 & 0 & 0 \\
\hline 11 & $\mathrm{G}$ & 0 & 0 & 165 & 233 & -60 & 160 \\
\hline 12 & $\mathrm{~S}$ & 0 & 0 & 395 & 235 & 0 & 300 \\
\hline 13 & $\mathrm{C}$ & 150 & 90 & 0 & 220 & 0 & 0 \\
\hline
\end{tabular}

The variables presented in Tables I and II are:

$R \quad$ - branch resistance;

$X \quad-$ branch inductive reactance;

$B \quad-$ branch capacitive susceptance;

$P_{c} \quad$ - active load power;

$Q_{c} \quad$ - reactive load power;

$P_{g} \quad$ - active generated power;

$U_{s p} \quad-$ specified voltage at generator buses;

$Q_{\min } \quad-$ minimum reactive power at generators;

$Q_{\max } \quad$ - maximum reactive power at generators;

$\mathrm{G}$ stands for generator buses, $\mathrm{C}$ stands for consumer/load buses, and S stands for the slack bus.

\section{A. TCSC placement on the TEST2 network}

Three scenario were considered for simulating a TCSC in the TEST2 network, that is the base case, increase in the load flow and decrease in the load flow. Also, Two candidate lines are considered that is the lines the border lines between the North and the South parts of the system, which are line 1-2 and line 9-10.

- Inserting a TCSC on the line 9-10

The purpose is to determine the TCSC reactance necessary to achieve a change in the power flow on the line 910 by $5 \mathrm{MW}$. The direction of power flow in the base case is from bus 10 to bus 9 .

Base case: $\quad P_{10-9}=17.278 \mathrm{MW}$

Power flow increase: $\quad P_{10-9}=22.278 \mathrm{MW}, \quad X_{\mathrm{TCSC}}=-69 \Omega$

Power flow decrease: $\quad P_{10-9}=12.278 \mathrm{MW}, X_{\mathrm{TCSC}}=117 \Omega$

The line loading and the voltage profile for the three scenario when considering a TCSC on the line 9-10 are presented in Figures 4 and 5.

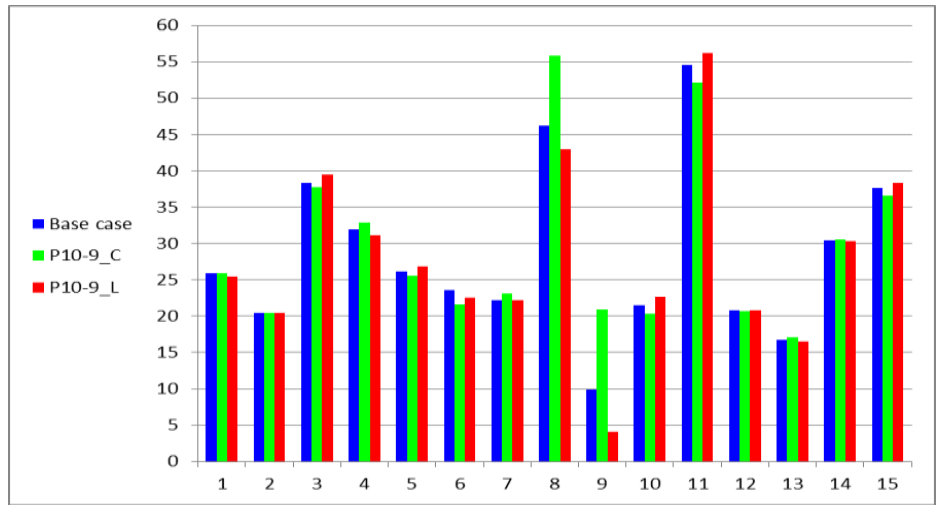

Fig.4 The line loading for TEST2, when TCSC installed on the line 10-9. 


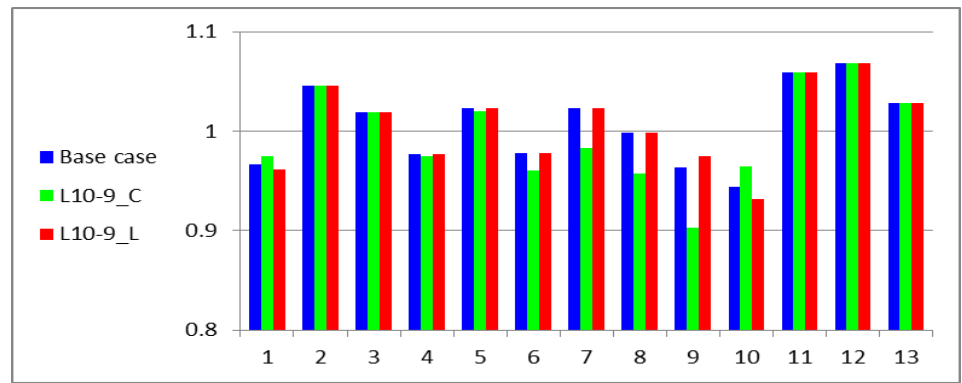

Fig.5 The voltage level in the bus for TEST2, when TCSC installed on the line 10-9.

- Inserting a TCSC on the line 1-2

The direction of power flow in the base case is from bus 2 to bus 1 .

Base case: $\quad P_{2-1}=77.968 \mathrm{MW}$

Power flow increase: $\quad P_{2-1}=82.968 \mathrm{MW}, X_{\mathrm{TCSC}}=-14 \Omega$

Power flow decrease: $\quad P_{2-1}=72.698 \mathrm{MW}, X_{\mathrm{TCSC}}=17 \Omega$

We can see that by increasing the power flow in the same direction as for the base case, the voltage at bus 10 is improved

The line loading and the voltage profile for the three scenario when considering a TCSC on the line 1-2 are presented in Figures 6 and 7.

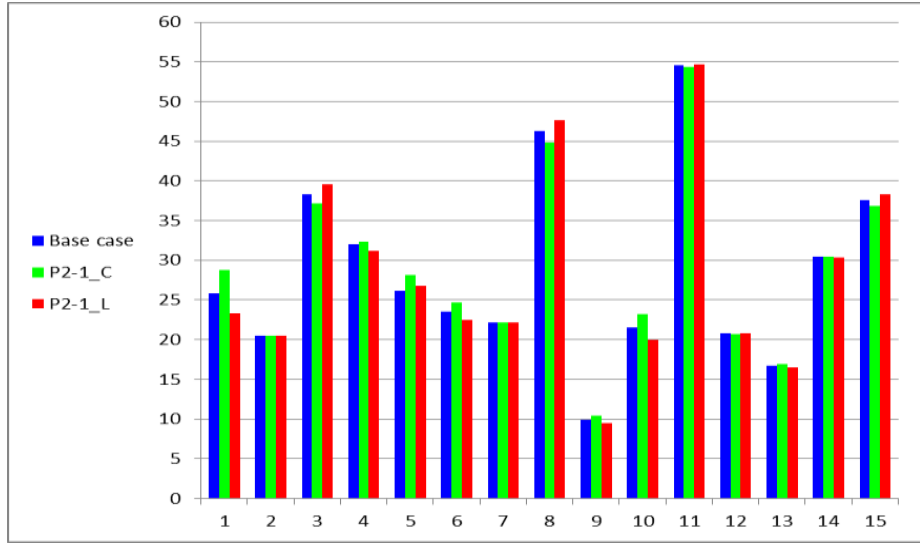

Fig.6 The line loading for TEST2, when TCSC installed on the line 2-1.

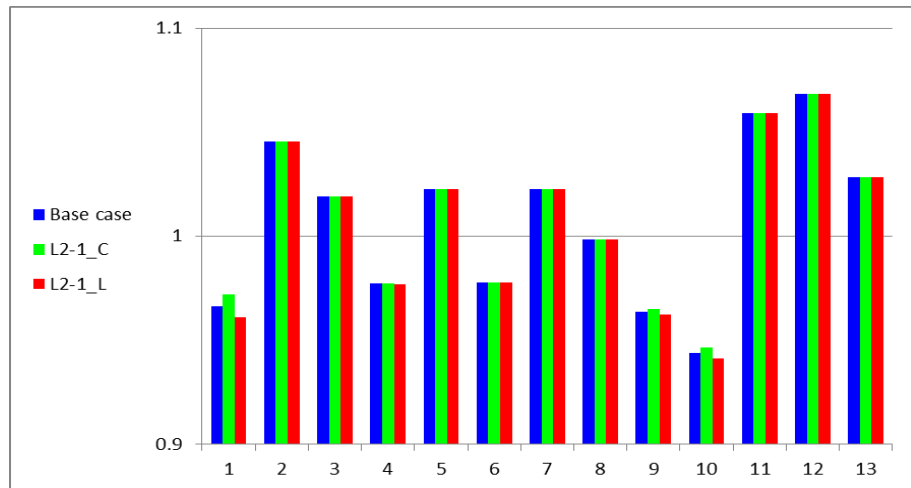

Fig.7 The voltage level in the bus for TEST2, when TCSC installed on the line 2-1.

\section{Conclusion}

Comparing the results from the two cases we may say that the reactance necessary for the same purpose if much bigger for the line 9-10 than for the line 1-2. On the other hand in the case of line 9-10, insertion of a TCSC is not effective because a very large device is require to achieve a small change in the power flow. This aspect can be influence by many factors, including the amount of power demand in the target area or the presence of generators in the direction of the power flow. Also, we may conclude that a TCSC may not be able to significantly change the power flow in large loops but probably in the case of parallel lines. 


\section{References}

[1]. Berizzi. A, Delfanti. M, Merlo. M, Pasquadibisceglie MS, "Congestion management in a zonal market by a neural network approach," European TRANS. Electrical Power, pp. 569-584, vol. 19. 2009

[2]. E. Gholipour, Sh. Saadate, "Improving of Transient Stability of Power Systems Using UPFC," IEEE TRANS. Power delivery, vol. 2, pp. 1677-1682, Apr. 2005.

[3]. S. Meikandasivam, Rajesh Kumar Nema, and Shailendra Kumar Jain, "Performance of Installed TCSC Projects", Department of Electrical Engineering, Maulana Azad National Institute of Technology, Bhopal, INDIA 978 8/11, 2011 IEEE.

[4]. J. Paserba, N. Miller, E. Larsen and R. Piwko, "A Thyristor Controller Series Compensation Model For Power System Stability Analysis," IEEE Transactions on Power Delivery, Vol. 10, No. 3, July 1995, Page(s),1471-1478.

[5]. E.W. Pahner and G. Ledwich, "Optimal Placement of Angle Transducers in Power System," IEEE Transactions on Power Systems, Vol. 11, No. 2, May 1996, pp. 788-793.

[6]. S.N. Singh, A.K. David, "Optimal location of FACTS devices for congestion management", Electric Power Syst. Res. 58, 71-79, June 2001.

[7]. FACTS Terms \& Definitions Task Force of the FACTS Working Group of the DC and FACTS Subcommittee, 'Proposed Terms and Definitions for Flexible AC Transmission System (FACTS) IEEE Transactions on Power Delivery, Vol.12, No.4, October 1997.

[8]. N.Christl, R.Hedin, P.E.Kraucs, P.Luetzelberger, S.M.McKenna, A.H.Montoya, K.Sadek, and D.R.Torgerson, 'Advanced Series Compensation (ASC) with Thyristor Controlled Impedance', CIGRE Paper 14/37/38-07, Paris, France, 1992.

[9]. J.Urbanek, R.J.Piwko, E.V.Larsen, B.Ldamsky, B.C.Furumasu, W.Mittlelstadt, J.D.Eden, 'Thyristor Controlled Series Compensation - Prototype Installation at Slatt 500kV Substation', IEEE Transaction on Power Delivery, pp.1460-1469, July 1995.

[10]. J.Liang, J.B.Guo, X.X. ZHOU, 'Analysis of the Yimin-Fengtun 500kV TCSC on the Northeast China power system', IFAC/CIGRE symposium on Control of power systems and power plants, CPSPP'97, Beijing, China,1997.

[11]. X.Zhou, J.Liang, 'Overview of control schemes for TCSC to enhance the stability of power systems', IEE proceedings, generation, transmission and distribution, Vol. 146, No.2, March 1999.

[12]. Stéphane Gerbex, Rachid Cherkaoui, and Alain J. Germond, “Optimal Location of Multi-Type FACTS Devices in a Power System by Means of Genetic Algorithms”, IEEE Trans.on Power Systems, vol. 16, no. 3, Aug ,2001.

[13]. Prashant Kumar Tiwari, Yog Raj Sood, "Optimal Location of FACTS Devices in Power System Using Genetic Algorithm" 2009 World Congress on Nature \& Biologically Inspired Computing, India, Dec. 2009.

[14]. A. Lashkar Ara, , A. Kazemi, and S. A. Nabavi Niaki, "Multiobjective Optimal Location of FACTS Shunt-Series Controllers for Power System Operation Planning", Trans. on Power delivery, vol. 27, no. 2, April 2012.

[15]. Galiana,K.Almeida,K.Toussaint,M.Griffin,J.Atanackovic,D.,Ooi,B.T.,an d McGillis,T, "Assessment and control of the impact of FACTS devices on power system performance" IEEE Transaction. on Power Systems, Vol.11, No.1, November1996.

[16]. N. G. Hingorani and L. Gyugyi, "Understanding FACTS concepts and technology of flexible AC transmission systems", IEEE Press, New York, 2000.

[17]. G. Glanzmann and G. Andersson, "Using FACTS devices to resolve congestions in transmission grids", In Proc. of CIGRE/IEEE PES International Symposium, San Antonio, USA, 2005.

[18]. M. Eremia, H. Crişciu, B. Ungureanu, C. Bulac, „Analiza asistată de calculator a regimurilor sistemelor electroenergetice (Eng.: Computer aided analysis of the power system states)". Technical Publisher, Bucharest, 1985. 